\title{
MÃE SOLTEIRA NÃO. MÃE SOLO! CONSIDERAÇÕES SOBRE MATERNIDADE, CONJUGALIDADE E SOBRECARGA FEMININA
}

\section{Lize Borges ${ }^{1}$}

Resumo: Cuida-se de um estudo sobre as mães solo na sociedade contemporânea, levando em consideração a depreciação histórica dessas mulheres pelo simples fato de serem mães e não integrarem um relacionamento matrimonial. Além da discriminação em razão do estado civil, questões como a igualdade de salários e oportunidades de inserção e ascensão no mercado trabalho, bem como a tripla jornada e a sobrecarga feminina no que tange ao trabalho de cuidado com os(as) filhos(as) foram abordadas no presente estudo tendo como base recentes dados estatísticos.

Palavras-chave: Mulher. Maternidade. Conjugalidade. Abandono Paterno. Trabalho de cuidado. Sobrecarga feminina.

\section{INTRODUÇÃO}

Mulheres que são mães, mas não estão inseridas em uma relação conjugal compõem uma numerosa realidade no Brasil, seja por meio de uma maternidade voluntária e planejada como a adoção unilateral ou por técnicas reprodutivas, seja por questões socioculturais como o abandono ou a omissão paterna.

O termo "mães solteiras", como eram conhecidas as mães solo, carrega o forte resquício da sociedade machista e patriarcal do século $X X$, em que a mulher - sobretudo a mulher casada - possuía seus direitos civis, sexuais e reprodutivos reduzidos e em sua maioria submetidos à vontade do marido.

\footnotetext{
${ }_{1}^{1}$ Advogada atuante na área de família e sucessões, especializada em Direito Civil pela Faculdade Baiana de Direito, mestra em Família na Sociedade Contemporânea pela Universidade Católica de Salvador, doutoranda em direito pela Universidade Federal de Bahia, integrante da Comissão Nacional de Direito e Arte do IBDFAM, presidente da comissão de Direito Internacional do IBDFAM/BA, integrante do International Society of Family Law (ISFL), pesquisadora do Grupo de Pesquisa em Direito e Sexualidade da Universidade Federal da Bahia (UFBA), professora de Direito Civil da Faculdade Batista Brasileira.
} 
Nesse mesmo cenário, o casamento era tido como a única possibilidade de constituição de família.

Alterações legislativas a exemplo do Estatuto da Mulher Casada (Lei no 4.121/1962), Emenda Constitucional do Divórcio (EC 9/77) e a Lei do Divórcio (Lei 6.515/77), Constituição Federal de 1988, Estatuto da Criança e do Adolescente (Lei no 8.069/90) e o Código Civil de 2002, foram essenciais não apenas para a emancipação feminina em todos os seus aspectos, como também para o alargamento do conceito de família, sobretudo na forma de sua constituição, para além do relacionamento conjugal.

Vale dizer que o reconhecimento das famílias monoparentais pela Constituição Federal de 1988 é um marco para as famílias formadas por uma pessoa e seus descendentes, posto que exclui a necessidade de relação conjugal para sua existência, inaugurando uma nova forma de constituição de família.

Por sua vez, princípios constitucionais da dignidade da pessoa humana, da igualdade e a própria proibição de diferença de salários, de exercício de funções e de critério de admissão por motivo de sexo, idade, cor ou estado civil também insculpidos na Constituição Federal de 1988 - e reiterados pela Consolidação das Leis do Trabalho - proporcionam questionamentos em relação à subsistência das mães solo.

Como então criar filhos(as) de forma solitária sem igualdade de oportunidades no âmbito do trabalho?

Para elaboração do presente estudo foram levantados diversos dados estatísticos que revelam mudanças expressivas no padrão social e consequentemente na sua dinâmica relacional dos indivíduos. Contudo, como restará demonstrado, também apontam a disparidade de gênero em relação a questões ao trabalho de cuidado com os(as) filhos(as), posto que as atividades que envolvem educação, criação e socialização destes são desempenhadas majoritariamente por mulheres, alertando para a naturalização do abandono paterno. 


\section{MÃE SOLTEIRA: PORQUE A CONJUGALIDADE IMPORTA TANTO?}

Durante muito tempo o termo utilizado para as mulheres com filhos(as) que não estavam inseridas em um relacionamento conjugal era "mãe solteira", posto que para a sociedade a conjugalidade era um fator essencial para que as mulheres pudessem se tornar mães.

O estado civil atrelado ao termo revela que a mulher casada goza de determinado status social não atribuído à mulher solteira, tampouco à mãe que não está inserida em um relacionamento conjugal, como se o casamento por si só fizesse-a atingir um melhor nível social. Nesse sentido, esclarece Simone de Beauvoir:

A mulher casada é autorizada a viver a expensas do marido; demais, adquire uma dignidade social muito superior à da celibatária. Os costumes estão longe de outorgar a esta possibilidades sexuais idênticas às do homem celibatário; a maternidade, em particular, é-lhe, por assim dizer, proibida, sendo a mãe solteira objeto de escândalo. Grifos Nossos (BEAUVOIR, pág. 176, 1970).

Como sabido o Brasil possui forte influência da Igreja Católica², que reconhecia o casamento como a única forma de constituição de família, não admitindo o desfazimento do vínculo matrimonial, senão pela morte. Quando a mulher não estava subordinada ao pai ou aos irmãos quando solteira, estava ao marido quando casada, pois mesmo com o status social que o matrimônio proporcionava, o papel da mulher na sociedade conjugal ainda era de submissão.

\footnotetext{
2 Nesse sentido, esclarece Orlando Gomes: "Fontes históricas do Direito de Família brasileira são, principalmente, o direito canônico e o direito português, representado este, sobretudo pelos costumes que os lusitanos trouxeram para o Brasil como seus colonizadores. A autoridade do direito canônico em matéria de casamento foi conservada até a lei de 1890 , que instituiu o casamento civil. A despeito da rechaçada, continuou a exercer, indiretamente, grande influência. A lei civil reproduziu várias regras do direito canônico, e algumas instituições eclesiásticas se transformaram em instituições seculares, tal como ocorreu, de regra, nos países católicos." (GOMES, pág. 22, 1976).
} 
Foi na sociedade machista e patriarcal do início do século $X X^{3}$ que Clóvis Bevilaqua insculpiu o Código Civil de 1916, que previa dentre outros dispositivos a exigência da virgindade da mulher no momento do casamento ${ }^{4}$, obrigatoriedade da mulher de acrescentar ao seu nome o sobrenome do marido ${ }^{5}$, proibia a investigação de maternidade cuja prole decorresse de relação havida fora do casamento ${ }^{6}$, extinguia o poder familiar das mães sobre os(as) filhos(as) havidos em relacionamento anterior, caso esta contraísse novas núpcias ${ }^{7}$ e incluía as mulheres casadas no rol de relativamente incapazes ${ }^{8}$, precisando de autorização do marido para herdar, trabalhar, alienar imóvel, aceitar mandato, litigar em juízo cível ou comercial, dentre outras limitações aos atos da vida civil.

\footnotetext{
${ }^{3}$ Como explica Silvio de Salvo Venosa: "Os Códigos elaborados a partir do século XIX dedicaram normas sobre a família. Naquela época, a sociedade era eminentemente rural e patriarcal, guardando traços profundos da família da Antiguidade. A mulher dedicava-se aos afazeres domésticos e a lei não lhe conferia os mesmos direitos do homem. O marido era considerado 0 chefe, o administrador e o representante da sociedade conjugal. Nosso Código Civil de 1916 foi fruto direto dessa época. Os filhos submetiam-se à autoridade paterna, como futuros continuadores da família, em uma situação muito próxima da família romana." (VENOSA, 2018).

4 Uma das formas de anulação do casamento era o erro essencial quanto à pessoa do outro $\mathrm{e}$ dentre as hipóteses de erro essencial, constava o "defloramento da mulher" sem prévio conhecimento do marido, dispositivo que só veio a ser efetivamente revogado quando da vigência do Código Civil de 2002. Vejamos:
}

Art. 218 do Código Civil de 1916: É também anulável o casamento, se houve por parte de um dos nubentes, ao consentir, erro essência quanto à pessoa do outro.

Art. 219 do Código Civil de 1916: Considera-se erro essencial sobre a pessoa do outro cônjuge:

(...)

IV. O defloramento da mulher, ignorado pelo marido (BRASIL, 2019).

${ }^{5}$ Art. 240 do Código Civil de 1916: A mulher assume, pelo casamento, com os apelidos do marido, a condição de sua companheira, consorte e auxiliar nos encargos da família (art. 324) (BRASIL, 2019).

${ }^{6}$ Art. 364 do Código Civil de 1916: A investigação da maternidade só se não permite, quando tenha por fim atribuir prole ilegítima à mulher casada, ou incestuosa à solteira (BRASIL, 2019).

7 Art. 393 do Código Civil de 1916: A mãe, que contrai novas núpcias, perde, quanto aos filhos do leito anterior, os direitos do pátrio poder (art. 329); mas, enviuvando, os recupera (BRASIL, 2019).

${ }^{8}$ Art. 6 do Código Civil de 1916: São incapazes, relativamente a certos atos (art. 147, n. 1), ou à maneira de os exercer:

I. Os maiores de dezesseis e menores de vinte e um anos (arts. 154 a 156).

II. As mulheres casadas, enquanto subsistir a sociedade conjugal.

III. Os pródigos.

IV. Os silvícolas (BRASIL, 2019). 
Nesse contexto, o percurso da emancipação feminina perpassa por determinadas alterações legislativas que proporcionaram paulatinamente a ampliação dos direitos civis, sexuais e reprodutivos da mulher. São elas:

a) o Estatuto da Mulher Casada (Lei no 4.121/1962) que alterou diversos artigos do Código Civil de 1916, retirando a mulher casada do rol das incapacidades e ampliando a sua autonomia em relação ao exercício de seus direitos civis; alterou a obrigatoriedade do acréscimo do sobrenome do marido, passando a ser uma faculdade; possibilitou também a contribuição da mulher nas decisões do interesse comum do casal e dos filhos e no próprio exercício do poder familiar, muito embora em caso de divergência deveria prevalecer a decisão do pai, ressalvado à mãe o direito de recorrer ao judiciário para sanar a divergência (BRASIL, 2019).

Dentre outros avanços previstos no Estatuto da Mulher Casada, autorizou a mulher a exercer a profissão que quisesse e, ainda, que a mãe que contraísse novas núpcias não mais perderia o poder familiar em relação aos filhos(as) da relação anterior, sendo, portanto, uma alteração legislativa de muita expressão no que tange ao direito das mulheres, sobretudo das mães;

b) a Emenda Constitucional do Divórcio (EC 9/77) e a Lei do Divórcio (Lei 6.515/77) que possibilitou o rompimento do vínculo matrimonial - que antes só acontecia com o evento morte - pelo divórcio e revogou o dispositivo do Código Civil de 1916 que previa o regime da comunhão universal como regra em caso de omissão dos cônjuges, elegendo o regime da comunhão parcial;

c) a Constituição Federal de 1988 que instaurou a igualdade entre homem e mulher, reiterou a dissolução do matrimônio pelo divórcio e alargou a proteção que é dada ao casamento passando a abarcar as uniões estáveis e a família monoparental reconhecendo-as como família ${ }^{9}$. Pertinente destacar os

\footnotetext{
${ }^{9}$ Art. 226 da Constituição Federal: A família, base da sociedade, tem especial proteção do Estado.

$\S 1^{\circ}$ O casamento é civil e gratuita a celebração.

$\S 2^{\circ}$ O casamento religioso tem efeito civil, nos termos da lei.
} 
princípios da dignidade da pessoa humana e da igualdade, insculpidos na Constituição Federal, que também beneficiam as mulheres, sobretudo no âmbito do trabalho em que houve a vedação de diferença de salários em relação ao gênero, raça, idade ou estado civil;

d) O Estatuto da Criança e do Adolescente (Lei no 8.069/90) estabeleceu diversas garantias e proteções à criança e ao adolescente, prevendo a igualdade de condições para o exercício do poder familiar pelo pai e pela mãe $e^{10}$

e) o Código Civil de 2002, fundado nos princípios norteadores da eticidade, sociabilidade e operabilidade também proporcionaram mudanças expressivas no direito das famílias, consagrando novos arranjos familiares, instituindo a chamada pluralidade familiar, respaldada em princípios como a afetividade, dignidade da pessoa humana, igualdade entre os filhos, solidariedade familiar e igualdade entre os cônjuges.

Acerca dos novos arranjos familiares que vem sendo abarcados pelo ordenamento jurídico brasileiro, as famílias monoparentais reconhecidas expressamente pela Constituição Federal de 1988 merecem o destaque, pois pela primeira vez na história foi reconhecido como família a entidade composta por qualquer dos pais e seus descendentes, ou seja, as famílias integradas por uma mulher e seu filho(a) passaram a ter os mesmos direitos das compostas pelo pai, a mãe e os filhos.

De acordo com Maria Berenice Dias (2016), "o enlaçamento dos vínculos familiares constituídos por um dos genitores com seus filhos, no âmbito

§ 3ํㅜ Para efeito da proteção do Estado, é reconhecida a união estável entre o homem e a mulher como entidade familiar, devendo a lei facilitar sua conversão em casamento.

$\S 4^{\circ}$ Entende-se, também, como entidade familiar a comunidade formada por qualquer dos pais e seus descendentes.

$\S 50$ Os direitos e deveres referentes à sociedade conjugal são exercidos igualmente pelo homem e pela mulher. (...) (BRASIL, 2018).

10 Art. 21 da Lei no 8.069/90 (Estatuto da Criança e do Adolescente): O poder familiar será exercido, em igualdade de condições, pelo pai e pela mãe, na forma do que dispuser a legislação civil, assegurado a qualquer deles o direito de, em caso de discordância, recorrer à autoridade judiciária competente para a solução da divergência (BRASIL, 2019). 
Revista Direito e Sexualidade

n. 1 (maio.2020)

da especial proteção do Estado, subtrai a conotação de natureza sexual do conceito de família". Ou seja, as famílias monoparentais acabaram inaugurando uma nova forma de família em que a conjugalidade não é uma imposição ou exigência legal.

As famílias anaparentais, aquelas formadas pela convivência de parentes ou pessoas a que se impõe o reconhecimento da relação familiar, também não carecem de conjugalidade para que se estabeleçam: é o caso de duas irmãs que conjugam esforços para a formação do acervo patrimonial (...). $\mathrm{Na}$ hipótese de falecimento de uma delas, descabe dividir os bens igualitariamente entre todos os irmãos (...) (DIAS, 2016)

Outra forma de família que também é insculpida em novos contornos é a família pluriparental ou recomposta, que é formada pela multiplicidade de vínculos, como por exemplo um casal que integra uma nova família, possuindo filhos(as) de relacionamentos anteriores. Nesses casos a dinâmica social, segundo Rolf Madaleno (2017) "quebrou a rigidez dos esquemas típicos de família, especialmente aquela centrada exclusivamente no casamento e permitiu se desenvolvessem novos modelos familiares".

O retrato da família não é mais a foto de um casamento (DIAS, 2019). Como visto, a conjugalidade vem ganhando novos contornos, sendo certo que fatores como a extrajudicialização do divórcio (Lei n 11.441/07) e a supressão do prazo para realização do divórcio (Emenda Constitucional $n^{\circ}$ 66/2010) contribuíram para o aumento substancial do número de divórcios no Brasil, sobretudo nos últimos anos (IBDFAM, 2019). E claro, a pessoa divorciada tem a liberdade de escolher casar-se novamente, constituir família por meio de uma união estável ou simplesmente escolher não ter novos vínculos conjugais, sobretudo porque o direito também passou a reconhecer as famílias unipessoais (BRASIL, 2019), formadas por um único indivíduo. O casamento, portanto, não é mais a única forma possível de constituição de família. 
Como forma de realização da maternidade, é possível citar a adoção unilateral, prevista no art. 42 do Estatuto da Criança e do Adolescente - ECA ${ }^{11}$, que expressamente dispensa a comprovação do estado civil para a adoção de crianças e adolescentes. Por sua vez, com o avanço científico outras formas de reprodução passaram a ser alternativas eficazes, como as técnicas de inseminação artificial e o congelamento de óvulos visando a postergação da maternidade (BASSETTE, 2019).

É possível afirmar que a maternidade não mais decorre da alteração do estado civil, da conjugalidade propriamente dita, mas sim da parentalidade, do desejo de tornar-se mãe, portanto, não é o marido ou companheiro que fazem tornam as mulheres mães, mas sim os(as) próprios(a) filhos(as).

\section{DO TRABALHO DE CUIDADO: A DISPARIDADE DE GÊNERO}

"Trabalhar como se não tivesse filhos, ser mãe como se não trabalhasse fora" (LIZAUKAS, 2019). Essa é uma conta que não fecha! A sobrecarga feminina no trabalho de cuidado foi objeto de pesquisa pelo PNAD (2018), tendo sido constatado que as mulheres que trabalham fora de casa dedicam cerca de 18,1 horas semanais às tarefas da casa, e cuidados com filhos e idosos, enquanto os homens desempregados ou inativos dedicam apenas 12 horas semanais às mesmas atividades.

Segundo a Primeiríssima Infância - Creche, dos casos analisados numa pesquisa divulgada em 2017 , restou constatado que $89 \%$ dos filhos de até 03 (três) anos de idade são cuidados pelas mães (MARTINS, 2019). Isso quer dizer que atividades como brincar, alimentar, cozinhar, dar banho, trocar a fralda, levar ao médico, lavar as roupas, arrumar a casa, levar à escola, ajudar nas tarefas escolares, dentre outras atividades que contemplam o trabalho de

\footnotetext{
${ }^{11}$ Art. 42. Podem adotar os maiores de 18 (dezoito) anos, independentemente do estado civil (BRASIL, 2019).
} 
Revista Direito e Sexualidade

n. 1 (maio.2020)

cuidado são em sua maioria desempenhadas por mulheres em flagrante disparidade de gênero.

Acerca da diferença de papeis do homem e da mulher na sociedade brasileira sobretudo no que diz respeito às construções sociais que atribuem o trabalho de cuidado na criação e socialização dos filhos à mulher, esclarece Heleieth Saffioti:

Não é difícil observar que homens e mulheres não ocupam posições iguais na sociedade brasileira. (...) A identidade social da mulher, assim como a do homem, é construída através da atribuição de distintos papeis, que a sociedade espera ver cumpridos pelas diferentes categorias de sexo. A sociedade delimita, com bastante precisão, os campos em que pode operar a mulher, da mesma forma como escolhe os terrenos em que pode atuar o homem. A socialização dos filhos, por exemplo, constitui tarefa tradicionalmente atribuída as mulheres. Mesmo quando a mulher desempenha uma função remunerada fora do lar, continua a ser responsabilizada pela tarefa de preparar as gerações mais jovens para a vida adulta. Grifos Nossos (SAFFIOTI, pág. 08, 1987).

Contudo o trabalho de cuidado que é atribuído às mulheres em relação as tarefas domésticas, a criação dos filhos, o cuidado com os idosos, apesar de integrar substancialmente a carga de trabalho semanal das mulheres, não é tido como trabalho propriamente dito, posto não ser dotado de valor de trabalho, notadamente por ser historicamente desenvolvido pelas mulheres no seio de uma sociedade patriarcal. Adverte Angela Davis (2016) que "como as tarefas domésticas não geram lucro, o trabalho doméstico foi naturalmente definido como uma forma inferior de trabalho, em comparação com a atividade assalariada capitalista".

O trabalho de cuidado, notadamente no que diz respeito à criação, educação e socialização dos(as) filhos(as) está intimamente ligado ao que a sociedade entende como "capacidade de ser boa mãe", perpassando por papéis sociais, ingressando novamente em conotações discriminatórias, como se a 
mulher não pudesse exercer determinados comportamentos e faculdades apenas pelo fato de ser mãe. É o que esclarece Maria Berenice Dias:

Limitações que não estão na lei acabam sendo impostas às mulheres com acentuada conotação discriminatória, pois não são exigidas dos homens. (...) Em se tratando de guarda de filhos, muitas vezes, é desconsiderada a liberdade da mulher. É feita uma avaliação comportamental de adequação a determinados papéis sociais. Inúmeros julgados estabelecem certa confusão entre a vida sexual da mulher e sua capacidade de ser boa mãe, não considerando aspectos afetivos e culturais para o pleno desenvolvimento dos filhos (DIAS, pág.161, 2016).

No caso das mães solo em específico, notadamente por serem o enfoque do presente trabalho, se faz necessário analisar porque a sobrecarga materna ainda é tão naturalizada pela sociedade, que por sua vez também naturaliza questões como o abandono paterno ou a omissão do pai em relação ao trabalho de cuidado, incorrendo na disparidade de gênero nesse ponto.

\subsection{DO ABANDONO PATERNO E A SOBRECARGA DA MÃE SOLO}

Se por um lado a mãe solo vem sofrendo historicamente com o preconceito por não estar inserida em uma relação conjugal, atendendo aos padrões impostos por pela sociedade, de outro o abandono paterno parece ser natural.

É claro que quando se fala de mãe solo, logo é suscitada a maternidade solitária de forma voluntária e planejada, como é o caso das mulheres que optam pela adoção unilateral ou mesmo a produção independente utilizando-se de técnicas de reprodução. Entretanto, se faz necessário chamar a atenção para o fato de que nesses casos o que funda a maternidade solitária é, acima de tudo, a escolha da mulher de ser mãe, em pleno exercício de sua autonomia da vontade, dos seus direitos reprodutivos, sexuais e do direito ao próprio corpo. 
Outro ponto que deve ser destacado é que, sobretudo nas técnicas de reprodução assistida, poucas são as mulheres que podem dispor dos expressivos valores que envolvem a realização desses procedimentos, sem prejuízo à sua subsistência. Ademais, se vislumbrada a realidade social em que as mães solo estão inseridas, o número de mulheres que efetivamente optam pela maternidade solitária de forma voluntária e planejada ainda representa um número tímido, se comparado, por exemplo, à realidade das mães solitárias decorrentes do abandono ou da omissão paterna.

Dito isso, as estatísticas apontam para um número cada vez maior de mães solo. De acordo com o IBGE em uma pesquisa divulgada em 2017, em 2005 o número de mulheres com filhos e sem cônjuge alcançava o montante de 10,5 milhões. Em 2015 esse número atingiu a marca de 11,6 milhões, demonstrando o acréscimo de 1,1 milhões (VELASCO, 2019). O Conselho Nacional de Justiça (2019) também revela dados que corroboram com essa realidade, haja vista que o relatório do Projeto Pai Presente tomou como base o Censo Escolar de 2011 realizado pelo Instituto Nacional de Estudos e Pesquisas Educacionais Anísio Teixeira (INEP), cujo resultado aponta para 5.494.267 milhões de crianças que não possuem o nome do pai em seus registros.

Expressões "romantizadas" atribuídas às mães solo como "mãe guerreira" e "pãe" - esta última que representa a cumulação de função de "pai" e mãe" - revelam não apenas o pai ausente, como a própria sobrecarga feminina no que que diz respeito ao trabalho de cuidado, que restará melhor explicado ao longo do presente estudo.

Apesar da Lei de Alimentos e o Código Civil de $2002^{12}$ reforçarem a ideia da obrigatoriedade de prestação dos alimentos entre pais e filhos(as) no

\footnotetext{
${ }^{12}$ Art. 1.694. Podem os parentes, os cônjuges ou companheiros pedir uns aos outros os alimentos de que necessitem para viver de modo compatível com a sua condição social, inclusive para atender às necessidades de sua educação.
}

\section{(...)}

Art. 1.695. São devidos os alimentos quando quem os pretende não tem bens suficientes, nem pode prover, pelo seu trabalho, à própria mantença, e aquele, de quem se reclamam, pode fornecê-los, sem desfalque do necessário ao seu sustento. 
que tange às questões materiais, não se pode deixar de observar a necessidade de partilha dos demais aspectos inerentes a educação e criação dos filhos, que no caso das mães solo, acaba representando a concentração dessas responsabilidades na figura da mulher.

Nesse sentido, explica Maria Berenice Dias (2016):

A obrigação parental não é somente o pagamento de alimentos. Há um leque de encargos que não se mensuram monetariamente. Mas nenhuma consequência é imposta a quem descumpre os deveres inerentes ao poder familiar. Separado o casal, o pai, na maioria dos casos, nem ao menos divide os deveres de criação e educação do filho, pois raramente reconhece sua responsabilidade de acompanhar o seu desenvolvimento. De forma frequente, não exerce sequer a obrigação de visitas. Os danos afetivos que decorrem dessa omissão não estão previstos como indenizáveis, mas a justiça vem, ainda que timidamente, impondo o pagamento (DIAS, pág.160, 2016).

Em outras palavras, o exercício da paternidade não se resume apenas e tão somente à "contribuição material" decorrente da prestação dos alimentos ou o exercício da convivência paterna limitada aos parquinhos dos shoppings aos finais de semana.

Em 2012, o Superior Tribunal de Justiça reconheceu o cuidado como valor jurídico integrante do ordenamento jurídico brasileiro não de forma expressa, mais implícito no art. 227 da Constituição Federal ${ }^{13}$, com o julgamento do Recurso Especial $n^{\circ} 1.159 .242 / S P^{14}$ que versava sobre reparação civil por abandono afetivo e material.

Art. 1.696. O direito à prestação de alimentos é recíproco entre pais e filhos, e extensivo a todos os ascendentes, recaindo a obrigação nos mais próximos em grau, uns em falta de outros.

${ }^{13}$ Art. 227. É dever da família, da sociedade e do Estado assegurar à criança, ao adolescente e ao jovem, com absoluta prioridade, o direito à vida, à saúde, à alimentação, à educação, ao lazer, à profissionalização, à cultura, à dignidade, ao respeito, à liberdade e à convivência familiar e comunitária, além de colocá-los a salvo de toda forma de negligência, discriminação, exploração, violência, crueldade e opressão (BRASIL, 2019).

14 CIVIL E PROCESSUAL CIVIL. FAMÍLIA. ABANDONO AFETIVO. COMPENSAÇÃO POR DANO MORAL. POSSIBILIDADE. 
$\mathrm{Na}$ oportunidade foi arbitrado o valor de $\mathrm{R} \$ 200.000,00$ (duzentos mil reais) como como forma de indenização ao constatado abandono paterno, tendo a Ministra Relatora, Nancy Andrighi, fundamentado sua decisão esclarecendo que o dever de cuidado também é um preceito legal:

Aqui não se fala ou se discute o amar e, sim, a imposicão biológica e legal de cuidar, que é dever jurídico, corolário da liberdade das pessoas de gerarem ou adotarem filhos.

O amor diz respeito à motivação, questão que refoge os lindes legais, situando-se, pela sua subjetividade e impossibilidade de precisa materialização, no universo meta-jurídico da filosofia, da psicologia ou da religião.

O cuidado, distintamente, é tisnado por elementos objetivos, distinguindo-se do amar pela possibilidade de verificação e comprovação de seu cumprimento, que exsurge da avaliação de ações concretas: presença; contatos, mesmo que não presenciais; ações voluntárias em favor da prole; comparações entre o tratamento dado aos demais filhos - quando existirem -, entre outras fórmulas possíveis que serão trazidas à apreciação do julgador, pelas partes.

Em suma, amar é faculdade, cuidar é dever (BRASIL, 2019).

1. Inexistem restrições legais à aplicação das regras concernentes à responsabilidade civil e o consequente dever de indenizar/compensar no Direito de Família.

2. O cuidado como valor jurídico objetivo está incorporado no ordenamento jurídico brasileiro não com essa expressão, mas com locuções e termos que manifestam suas diversas desinências, como se observa do art. 227 da CF/88.

3. Comprovar que a imposição legal de cuidar da prole foi descumprida implica em se reconhecer a ocorrência de ilicitude civil, sob a forma de omissão. Isso porque o non facere, que atinge um bem juridicamente tutelado, leia-se, o necessário dever de criação, educação e companhia - de cuidado - importa em vulneração da imposição legal, exsurgindo, daí, a possibilidade de se pleitear compensação por danos morais por abandono psicológico.

4. Apesar das inúmeras hipóteses que minimizam a possibilidade de pleno cuidado de um dos genitores em relação à sua prole, existe um núcleo mínimo de cuidados parentais que, para além do mero cumprimento da lei, garantam aos filhos, ao menos quanto à afetividade, condições para uma adequada formação psicológica e inserção social.

5. A caracterização do abandono afetivo, a existência de excludentes ou, ainda, fatores atenuantes - por demandarem revolvimento de matéria fática - não podem ser objeto de reavaliação na estreita via do recurso especial.

6. A alteração do valor fixado a título de compensação por danos morais é possível, em recurso especial, nas hipóteses em que a quantia estipulada pelo Tribunal de origem revela-se irrisória ou exagerada.

7. Recurso especial parcialmente provido (BRASIL, 2019). 
Tem-se, pois, que o abandono e omissão paterna, não apenas no aspecto material, como intelectual, moral, psicológico, educacional e mesmo em decorrência do próprio dever de cuidado é uma realidade numerosa que incorre na sobrecarga da mulher no acúmulo de tantas funções.

\section{DA SUSBSISTÊNCIA DA MÃE SOLO E A DESIGUALDADE DO MERCADO DE TRABALHO: A REALIDADE EM NÚMEROS}

Como visto, a mãe solo carrega um preconceito histórico pelo fato de não estar inserida em uma relação conjugal e ainda desempenhar constantemente atividades não remuneradas no que tange ao trabalho de cuidado dos filhos(as). Não obstante, a mulher também é discriminada quando se trata de igualdade de salários e oportunidades de ascensão no mercado de trabalho.

Muito embora haja expressa vedação de discriminação em razão do sexo, prevista na Constituição Federal de $1988^{15}$ e reiterada em diversos dispositivos da Consolidação das Leis do Trabalho (Decreto-Lei no $5.452 / 1943)^{16}$, salta aos olhos os resquícios do patriarcado ainda tão presentes na sociedade machista contemporânea.

\footnotetext{
${ }^{15}$ Art. $7^{\circ}$ da CF/88: São direitos dos trabalhadores urbanos e rurais, além de outros que visem à melhoria de sua condição social: (...)

XXX - proibição de diferença de salários, de exercício de funções e de critério de admissão por motivo de sexo, idade, cor ou estado civil. (BRASIL, 2018)

${ }^{16}$ Art. 5o - A todo trabalho de igual valor corresponderá salário igual, sem distinção de sexo (BRASIL, 2018).

Art. 373-A da CLT Ressalvadas as disposições legais destinadas a corrigir as distorções que afetam o acesso da mulher ao mercado de trabalho e certas especificidades estabelecidas nos acordos trabalhistas, é vedado:

I - publicar ou fazer publicar anúncio de emprego no qual haja referência ao sexo, à idade, à cor ou situação familiar, salvo quando a natureza da atividade a ser exercida, pública e notoriamente, assim o exigir;
} 
Isto porque, segundo dados divulgados pelo IBGE (2017), tem-se que a taxa de pobreza por família é maior entre as famílias compostas por mulheres sem cônjuge e com filhos(as). Ademais, os dados obtidos por Manso, Toledo e Burgarelli (2019) com o sistema lbope apontam que em São Paulo/SP as chances de ser mãe solo na periferia é até 3,5 vezes maior do que nas demais zonas da cidade.

Apesar da vedação de diferença de salários em relação ao gênero, raça, idade ou estado civil, fato é que pesquisas apontam que as mulheres ganham menos que os homens em todas as áreas e cargos, sendo certo que a discrepância entre os salários pode alcançar o patamar de até 53\% (cinquenta e três por cento), somado ao fato de que as mulheres ainda são minoria nos cargos de gestão (CAVALLINI, 2019).

Se faz necessário analisar a questão da própria subsistência, inserção no mercado de trabalho e igualdade de oportunidades sob a perspectiva do gênero, raça e classe, haja vista que segundo dados da Pesquisa Nacional por Amostra de Domicílios (PNAD) as mulheres negras ganham em média 46\% (quarenta e seis porcento) da remuneração dos homens brancos. São elas que têm a menor renda entre os trabalhadores com ensino superior (BELLONI, 2019).

II - recusar emprego, promoção ou motivar a dispensa do trabalho em razão de sexo, idade, cor, situação familiar ou estado de gravidez, salvo quando a natureza da atividade seja notória e publicamente incompatível;

III - considerar o sexo, a idade, a cor ou situação familiar como variável determinante para fins de remuneração, formação profissional e oportunidades de ascensão profissional;

IV - exigir atestado ou exame, de qualquer natureza, para comprovação de esterilidade ou gravidez, na admissão ou permanência no emprego;

V - impedir o acesso ou adotar critérios subjetivos para deferimento de inscrição ou aprovação em concursos, em empresas privadas, em razão de sexo, idade, cor, situação familiar ou estado de gravidez;

$\mathrm{VI}$ - proceder o empregador ou preposto a revistas íntimas nas empregadas ou funcionárias.

Art. 461. Sendo idêntica a função, a todo trabalho de igual valor, prestado ao mesmo empregador, no mesmo estabelecimento empresarial, corresponderá igual salário, sem distinção de sexo, etnia, nacionalidade ou idade (BRASIL, 2019). 
Há que se falar, ainda, na discriminação da mulher no mercado de trabalho apenas por ser mãe, o que pode ser observado da pesquisa realizada pela Fundação Getúlio Vargas (FGV), em que restou constatado que metade das mulheres fica desempregada um ano após o início da licença maternidade, seja em razão de demissão, seja porque decidiu sair do emprego (METADE DAS, 2019).

Nesse sentido, deve-se confrontar os números que retratam a realidade social e a efetividade dos direitos e garantias constitucionais no que diz respeito à não discriminação, sendo possível afirmar que a teoria é diferente da prática nesse ponto. Ora, conforme se extrai dos dados mencionados, não há igualdade entre homens e mulheres em relação à remuneração e oportunidades no mercado de trabalho.

Acerca do princípio da igualdade, insculpido na Constituição Federal de 1988, Maria Berenice Dias (2016). adverte que "a igualdade formal vem decantada enfaticamente, mas tal não basta, por si só, para alcançar a absoluta equivalência social e jurídica de homens e mulheres".

Mesmo na busca por inserção no mercado de trabalho, as mulheres com filhos(as) são prejudicadas apenas pelo fato de serem mães. É o que diz um estudo realizado pela American Journal of Sociology, que apontou que em uma oportunidade de contratação em que as candidatas sejam iguais em todos os aspectos, havendo uma sutil indicação de que uma delas é mãe, a probabilidade da mãe ser escolhida é reduzida em $37 \%$ (trinta e sete porcento) (GOLDSTEIN, 2019).

Nesse ponto, pertinente destacar a "romantização" do empreendedorismo materno, tendo em vista que o alto índice de desemprego faz com que as mães se lancem no mercado como empreendedoras não porque sonham abrir uma empresa, mas por necessidade de reinserção no mercado após a maternidade - é o que aponta a pesquisa realizada pelo Global Entrepreneurship Monitor (GEM) 2016 em parceria com o SEBRAE e a IBPQ (POR NECESSIDADE, 2019). 
Verifica-se que a maternidade acaba sendo um fator determinante no que diz respeito a inserção da mulher no mercado de trabalho e na sua própria subsistência, levando em consideração a constatada desigualdade de oportunidades e de remuneração. Ao que parece, as mulheres ainda precisam escolher entre a maternidade e a realização profissional, como se escolher as duas opções fosse algo incompatível ou de difícil conciliação com os parâmetros da sociedade. Nesse sentido, explica Pierre Bourdieu:

\begin{abstract}
"A verdade das relações estruturais de dominação sexual se deixa realmente entrever a partir do momento em que observamos, por exemplo, que as mulheres que atingiram os mais altos cargos (chefe, diretora em um ministério etc.) têm que "pagar", de certo modo, por este sucesso profissional com um menor "sucesso" na ordem doméstica (divórcio, casamento tardio, celibato, dificuldades ou fracassos com os filhos etc.) e na economia de bens simbólicos (...)" (BOURDIEU, pág. 126, 2012).
\end{abstract}

Resta claro que apesar do ordenamento jurídico brasileiro fornecer uma série de sustentáculos para possibilitar uma vida digna, justa, igualitária entre homens e mulheres, fato é que as mulheres, sobretudo as mães solo, enfrentam - além da persistente discriminação por não estar inserida em uma relação conjugal - a flagrante dificuldade de subsistência, no sentido de manter a si própria e seus filhos(as), seja por dificuldade de inserção ou pelo preconceito que enfrentam no mercado de trabalho, impactando diretamente no sustento, na educação e na qualidade de vida proporcionada aos filhos(as).

\title{
CONCLUSÃO
}

A sociedade machista e patriarcal do início século XX serviu como base para a elaboração do Código Civil de 1916, em que a mulher - sobretudo a mulher casada - tinha seus direitos civis, sexuais e reprodutivos limitados e em sua maioria deviam observar à vontade de uma homem: do pai ou irmão se solteira e do marido, se casada. 
Revista Direito e Sexualidade

n. 1 (maio.2020)

Nessa esteira, questões inerentes às decisões sobre a vida em comum ou mesmo a vida dos(as) filhos(as) estavam igualmente sujeitadas à vontade do marido, limitando a mulher o exercício da parentalidade em igualdade. $O$ casamento à época era a única forma de constituição de família, portanto, para que a maternidade fosse socialmente aceitada, a mulher necessariamente deveria estar inserida em um relacionamento matrimonial, estabelecendo uma forte dependência entre a maternidade e a conjugalidade.

A utilização do termo "mãe solteira" com a valorização do estado civil em sua composição, não passa de resquícios da sociedade dessa época, cujo preconceito persiste até os dias atuais, apesar das relevantes alterações legislativas realizadas.

Nesse ponto, pertinente destacar o advento do Estatuto da Mulher Casada (Lei o 4.121/1962) que dentre outras providências, retirou a mulher casada do rol de incapacidades e ampliou seus direitos civis, possibilitando a contribuição nas decisões familiares e da vida dos(as) filhos(as). A Emenda Constitucional do Divórcio (EC 9/77) e a Lei do Divórcio (Lei 6.515/77), por sua vez, trouxe novos contornos às relações matrimoniais, posto que antes eram indissolúveis, senão pela morte, passando a ser possível sua dissolução pelo divórcio.

Contudo, foi a Constituição Federal de 1988 trouxe não só novos contornos familiares - ante o reconhecimento da família monoparental e àquela constituída não pelo casamento, mas pela união estável - como também insculpiu os princípios da dignidade da pessoa humana, igualdade (sobretudo entre homem e mulher) e a proibição de diferença de salários, de exercício de funções e de critério de admissão por motivo de sexo, idade, cor ou estado civil. Por sua vez, o Código Civil de 2002 também corrobora com as novas demandas da sociedade contemporânea no que tange aos novos arranjos familiares, abarcando a pluralidade familiar.

Resta claro que atualmente o termo "mãe solteira" é deveras ultrapassado para utilizar como denominação das mulheres com filhos(as) que 
Revista Direito e Sexualidade

n. 1 (maio.2020)

não estão inseridas em um relacionamento matrimonial, vez que a alteração do estado civil atualmente em nada influencia na realização da maternidade. Ora, quem faz das mulheres mães não são os maridos, mas sim os(as) próprios(as) filhos(as)!

Vale dizer que quando se fala em mãe solo, logo se pensa na maternidade solitária de forma voluntária e planejada, a exemplo da adoção unilateral ou a utilização de recursos tecnológicos para a produção independente como as técnicas de reprodução assistida, que ainda representam uma tímida realidade entre as mulheres, se comparado aos registros alarmantes dos casos de abandono paterno.

Expressões atribuídas às mães solo como "mães guerreiras" e "pães" - esta última que representa a cumulação de função de "pai" e mãe" - são utilizadas popularmente para esconder o pai ausente e enaltecer a sobrecarga feminina no que que diz respeito ao trabalho de cuidado.

Nesse aspecto, foram levantados dados estatísticos no presente estudo que comprovam a disparidade de gênero em relação:

a) a sobrecarga feminina em relação ao trabalho de cuidado com os(as) filhos(as), tendo em vista a superior quantidade de horas semanais que as mulheres dedicam a esse trabalho invisível - posto ser historicamente desempenhado por mulheres e não ser remunerado como atividades assalariadas;

b) a naturalização do abandono paterno, diante do expressivo número de crianças e adolescentes que não possuem o nome do pai em seus registros, além da ausência de participação no trabalho de cuidado dos(as) filho(as), cujo dever de cuidar foi reconhecido pelo Superior Tribunal de Justiça com o julgamento inédito do Recurso Especial no 1.159.242 - SP (2009/0193701-9);

c) a desigualdade de salários e oportunidades de inserção e ascensão da mulher no mercado de trabalho e a consequente discriminação em razão do gênero; 
d) a falta de efetividade das normas garantidoras de igualdade de direitos e deveres entre homens e mulheres, tendo em vista que muito embora existam, carecem de efetividade, pois os números revelam que há práticas discriminatórias, sobretudo no mercado de trabalho;

d) a discriminação da mulher no mercado de trabalho apenas por ser mãe, posto que as chances da mulher sair do trabalho após a maternidade, seja em razão de demissão, seja por opção própria - ao que se deve considerar questões como carga horária, amamentação e outras práticas discriminatórias no ambiente de trabalho - são altas e, ainda, que na disputa por uma oportunidade de emprego a possibilidade de contratação de uma mulher diminui expressivamente caso esta seja mãe.

Não restam dúvidas que apesar das normas garantidoras de direitos, as mães solo enfrentam diversas formas de discriminação, desde o fato de não estarem inseridas em um relacionamento conjugal que decorre dos resquícios de uma sociedade machista e patriarcal, até questões que impactam sua vida na prática e de forma cotidiana, como a sobrecarga do trabalho de cuidado com os(as) filhos(as), a dificuldade de inserção e ascensão no mercado de trabalho e a desigualdade dos salários para desempenho das mesmas atividades, influenciando o não apenas a sua sobrevivência, como a de sua prole.

\section{REFERÊNCIAS BIBLIOGRÁFICAS}

BASSETTE, Fernanda. Brasileiras triplicam busca por congelamento de óvulos para adiar maternidade. BBC News. São Paulo, 21 set 2018. Disponível em: https://www.bbc.com/portuguese/geral-45325932 > Acesso em: 16 jul. 2019.

BEAUVOIR, Simone de. O Segundo Sexo, 1. Fatos e Mito. Difusão Europeia do Livro, São Paulo 1970, p. 176

BELLONI, Luiza. Mulher negra graduada no Brasil recebe $43 \%$ do salário de homem branco. Huffpost Brasil. São Paulo, 16 nov de 2017. Disponível em: < https://www.huffpostbrasil.com/2017/11/16/mulher-negra-graduada-no-brasil- 
Revista Direito e Sexualidade

n. 1 (maio.2020)

recebe-43-do-salario-de-homem-branco a 23279872/ > Acesso em: 16 de jul. 2019.

BOURDIEU, Pierre. A dominação masculina. Tradução: Maria Helena Küher, $11^{\underline{a}}$ ed. Rio de Janeiro: Bertrand, 2012.

BRASIL. Código Civil. Lei oㅜ 3.071, 1ํ jan de 1916. Revogada pela Lei ํㅜ 10.406 de 2002. Disponível em < http://www.planalto.gov.br/ccivil 03/leis/L3071.htm>. Acesso em: 16 jul. 2019.

BRASIL. Código Civil. Lei o 10.406, 10 jan de 2002. Institui o Código Civil. Disponível em: <http://www.planalto.gov.br/ccivil 03/leis/2002/10406.htm>. Acesso em: 22 jul. 2019.

BRASIL. Superior Tribunal de Justiça. Súmula o 364. Súmula 364 - 0 conceito de impenhorabilidade de bem de família abrange também o imóvel pertencente a pessoas solteiras, separadas e viúvas. Disponível em< https://scon.sti.jus.br/SCON/sumanot/toc.jsp\#TIT1TEMA0> . Acesso em: 16 jul. 2019.

2019.

BRASIL, Superior Tribunal de Justiça. Recurso Especial no 1.159.242. Disponível em:

https://ww2.sti.jus.br/processo/jsp/revista/abreDocumento.jsp? componente=CO L\&sequencial=14828610\&formato=PDF>. Acesso em: 22 jul. 2019

BRASIL. Decreto-lei no 5.452, 1ำ maio de 1943. Aprova a Consolidação das Leis do Trabalho. Disponível em: < http://www.planalto.gov.br/ccivil 03/decretolei/del5452.htm>. Acesso em 21 jul. 2019.

BRASIL. Lei no 4.121, 27 de Agosto de 1962. Dispõe sobre a situação jurídica da mulher casada. Disponível em: < http://www.planalto.gov.br/ccivil 03/leis/1950-1969/14121.htm>. Acesso em: 16 jul. 2019.

BRASIL. Lei no 8.069, 13 de Julho de 1990. Dispõe sobre o Estatuto da Criança e do Adolescente e dá outras providências. Disponível em: < http://www.planalto.gov.br/ccivil 03/leis//8069.htm>. Acesso em: 16 jul. 2019.

BRASIL. Constituição 1988. Constituição da República Federativa do Brasil: texto constitucional promulgado em 5 de outubro de 1988, com as alterações adotadas pelas Emendas constitucionais nos 1/1992 a 99/2017, pelo Decreto legistlativo no 186/2008 e pelas Emendas Constitucionais de revisão nos 1 a 6/1994. - 53. Ed., 1 reimpressão - Brasília: Câmara dos Deputados, Edições Câmara, 2018. 
Revista Direito e Sexualidade

n. 1 (maio.2020)

CAVALLINI, Marta. Mulheres ganham menos que os homens em todos os cargos e áreas, diz pesquisa. Portal G1. São Paulo, 07 mar de 2018. Disponível em < https://g1.globo.com/economia/concursos-e-emprego/noticia/mulheresganham-menos-que-os-homens-em-todos-os-cargos-e-areas-dizpesquisa.ghtml > Acesso em: 16 jul. 2019.

CONSELHO NACIONAL DE JUSTIÇA (CNJ). Cartilha DO Projeto Pai Presente $<$ http://www.cnj.jus.br/files/conteudo/destaques//arquivo/2015/04/b550153d316 d6948b61dfbf7c07f13ea.pdf> Acesso em: 28 jul. 2019.

DAVIS, Angela, 1944. Mulheres, Raça e Classe / Angela Davis: tradução de Heci Regina Candiani - 1르 ed. - São Paulo, Boitempo, 2016. p 230

DIAS, Maria Berenice. Manual de Direito das Famílias [livro eletrônico]. 4 ed. São Paulo Editora Revista dos Tribunais, 2016.

GOLDSTEIN, Katherine. The Open Secret of Anti-Mom Bias at Work. The New York Times, Nova lorque, 16 mai 2018. Disponível em: < https://www.nytimes.com/2018/05/16/opinion/workplace-discriminationmothers.html > Acesso em: 16 jul. 2019

GOMES, Orlando. Direito de Família. 2ª Edição. Editora Forense, Rio de Janeiro. Pág. 22, 1976.

IBDFAM. Em 33 anos, divórcios aumentam 269\%, enquanto a população cresceu apenas 70\% Disponível em: < http://ibdfam.org.br/noticias/namidia/16311/> Acesso em: 16 jul. 2019.

IBGE. Pesquisa Nacional por Amostra de Domicílios Contínua PNAD. Rio de Janeiro, 2018.

Disponível em: <https://www.ibge.gov.br/estatisticas/sociais/trabalho/17270pnadcontinua.html?ediçã

o=20636\&t=sobre $>$. Acesso em: 16 jul. 2019.

IBGE. Síntese de indicadores sociais: uma análise das condições de vida da população brasileira. Coordenação de População e Indicadores Sociais. Rio de Janeiro:, 2017.2 Disponível em <https://biblioteca.ibge.gov.br/visualizacao/livros/liv101459.pdf > Acesso em: 16 jul. 2019.

LISAUKAS, Rita. Ser mãe é padecer na internet. Trabalhar como se não tivesse filhos, ser mãe como se não trabalhasse fora. Disponível em: < https://emais.estadao.com.br/blogs/ser-mae/trabalhar-como-se-nao-tivessefilhos-ser-mae-como-se-nao-trabalhasse-fora/ > Acesso em: 16 jul. 2019.

MADALENO, Rolf. 1954 - Direito de família / Rolf Madaleno. - 7.․e ed. rev., atual. e ampl. - Rio de Janeiro: Forense, 2017. 
MARTINS, Helena. Mães são responsáveis pela criação dos filhos até 3 anos em $89 \%$ dos casos. Agência Brasil. Fortaleza, 7 nov de 2017. Disponível em: < http://agenciabrasil.ebc.com.br/geral/noticia/2017-11/maes-sao-responsaveispela-criacao-dos-filhos-ate-3-anos-em-89-dos-casos > Acesso em: 16 jul. 2019.

MANSO, Bruno; DE TOLEDO, José Roberto; BURGARELLI, Rodrigo. Chance de ser mãe solteira na periferia é até 3,5 vezes maior. Estadão. São Paulo, 12 mai de 2013. Disponível em: < https://saopaulo.estadao.com.br/noticias/geral,chance-de-ser-mae-solteira-na-periferia-eate-3-5-vezes-maior-imp-,1030951 > Acesso em: 16 jul. 2019.

METADE DAS mulheres brasileiras fica desempregada um ano após ter filho. Época negócios. São Paulo 5 set de 2017. Disponível em: < https://epocanegocios.globo.com/Carreira/noticia/2017/09/metade-dasmulheres-brasileiras-fica-desempregada-um-ano-apos-ter-filho.html $>$ Acesso em: 16 jul. 2019.

POR NECESSIDADE, mulheres começam a empreender após maternidade. Agência Sebrae de notícias. Brasília, 9 mai 2005. Disponível em: < https://revistapegn.globo.com/Mulheres-empreendedoras/noticia/2018/05/pornecessidade-mulheres-comecam-empreender-apos-maternidade.html $>$ Acesso em: 16 jul. 2019.

SAFFIOTI, Heleieth I.B. O poder do macho. Sao Paulo: Moderna. (Coleção polemica) p. 08. 1987.

VELASCO, Clara. Em 10 anos, Brasil ganha mais de 1 milhão de famílias formadas por mães solteiras. Portal G1. São Paulo, 15 mai de 2017. Disponível em < https://g1.globo.com/economia/noticia/em-10-anos-brasil-ganha-mais-de1-milhao-de-familias-formadas-por-maes-solteiras.ghtml > Acesso em: 16 jul. 2019.

VENOSA, Silvio de Salvo. Direito Civil: Direito de Família. 18. ed. - São Paulo : Atlas, 2018. 